(2) Open Access Full Text Article

REVIEW

\title{
Gore excluder device with the C3 delivery system for management of abdominal aortic aneurysm
}

This article was published in the following Dove Press journal:

Open Access Surgery

24 February 2012

Number of times this article has been viewed

Cheong J Lee

Mark L Keldahl

Mark D Morasch

Division of Vascular Surgery, Northwestern University Feinberg School of Medicine, Chicago, IL, USA
Correspondence to: Mark D Morasch Division of Vascular Surgery, Northwestern University,

676 North St Clair, Suite 650

Chicago, IL 606 II, USA

Tel +I 3126952716

Fax + I 3126954955

Email mmorasch@nmh.org
Abstract: The GORE Excluder stent-graft is one of the currently available devices approved by the US Food and Drug Administration for use in endovascular aortic repair. Recently, a new delivery system modification has been applied to the Excluder device which allows repositioning of the stent-graft to adjust for accurate proximal landing and facilitate gate cannulation. In this review, we examine the Excluder device with the new $\mathrm{C} 3$ delivery system and its potential benefit in the management of abdominal aortic aneurysms.

Keywords: gore excluder, abdominal aortic aneurysm, repair, C3 delivery system

\section{Introduction}

Ruptured aneurysm is the 15 th leading cause of death in the US, with approximately 15,000 deaths occurring per year. ${ }^{1}$ The prevalence of asymptomatic abdominal aortic aneurysm (AAA) in men and women aged $>60$ years is estimated to be $4 \%-8 \%$ and $0.5 \%-1.5 \%$, respectively, and is known to increase with age. ${ }^{1}$ Open surgical repair to treat AAA has been performed for many years with good outcomes. However, despite advances in technique and perioperative recovery, the procedure still entails significant morbidity to the patient.

Parodi et al were the first to report the use of an endovascular stent-graft for treatment of an AAA in 1991. ${ }^{2}$ Twenty years later, endovascular aortic repair has become standard for patients with anatomically suitable AAAs. A number of large, randomized, controlled trials have confirmed that endovascular aortic repair does indeed demonstrate excellent short-term and mid-term outcomes when compared with open repair. ${ }^{3,4}$ However, these studies were based on older generation devices. Endografts have evolved rapidly based on clinical experience and data identifying deficiencies in older models. As such, long-term outcomes of endovascular aortic repair using the current generation devices still need to be examined and defined.

Based on a report from the EUROSTAR registry, all modern stent-grafts perform reasonably well. There is no one device that is clearly superior in short-term and mid-term follow-up. ${ }^{5,6}$ In essence, desirable endovascular aortic repair outcomes are dispersed among the various stent-grafts and the differences in device design and delivery systems allow for individualized graft selection that best suit the patient's specific anatomy.

\section{Excluder stent graft}

The Gore Excluder stent-graft (WL Gore and Associates, Flagstaff, AZ), now in its third generation, is one of the currently available endovascular aortic repair devices 
approved by the US Food and Drug Administration. Since its release in 1997, over 112,000 devices have been implanted ${ }^{7}$ and numerous studies have demonstrated the efficacy, safety, and durability of the Excluder device. ${ }^{8,9}$ Strengths include simplicity in design that employs a flexible, low profile, catheter-mounted delivery system. The device is a modular stent-graft consisting of a bifurcated main body with a single docking limb and assorted iliac limbs and iliac and proximal extension stent-grafts (Figure 1). The Excluder grafts are constructed with expanded polytetrafluoroethylene (ePTFE) and supported by a nitinol stent frame. Barbs are incorporated on the proximal neck of the main body for active infrarenal fixation. These barbs effectively prevent distal stent-graft migration. The main body of the device is constrained in an ePTFE jacket that is stitched with a single strand of ePTFE string. When the string is pulled, the stitches are released, causing a rapid graft deployment of the device in a proximal to distal fashion. The limbs of the Excluder are very flexible and reasonably accommodate complex iliac anatomies. The current indications for use (IFU) for the Gore Excluder stent-graft requires an infrarenal aortic neck diameter within a 19-29 mm range and a minimum aortic neck length of $15 \mathrm{~mm}$; proximal aortic neck angulation $\leq 60^{\circ}$, an iliac artery treatment diameter range of $8-18.5 \mathrm{~mm}$, and an iliac distal vessel seal zone length of at least $10 \mathrm{~mm}$. The required iliac and femoral access should accommodate introducer sheaths of 12,18 , and 20 French in diameter.

A number of design improvements to the Excluder have been made over the last decade. One of the most notable changes involved modification of the ePTFE fabric. The original ePTFE microstructure and porosity increased fluid permeation through the device. Aneurysm sac enlargement developed in a subset of patients. ${ }^{10}$ This was attributed to endotension. A low porosity Excluder stent-graft was introduced in 2004. The new device added a thin, nonpermeable layer to the ePTFE fabric. Post-marketing clinical studies have demonstrated that addition of the low permeability layer provided for a reduced incidence of sac enlargement when compared with the original version, and the new device was found to be associated with early aneurysm sack shrinkage. ${ }^{11,12}$

A crucial step during device deployment is the accurate placement of the proximal main body in relation to the lowest renal artery orifice. In late 2010, the Excluder device deployment system was modified for the purposes of allowing a more precise and controlled proximal deployment. A unique characteristic of the Excluder device, prior to the modification, had been its rapid deployment mechanism. Although

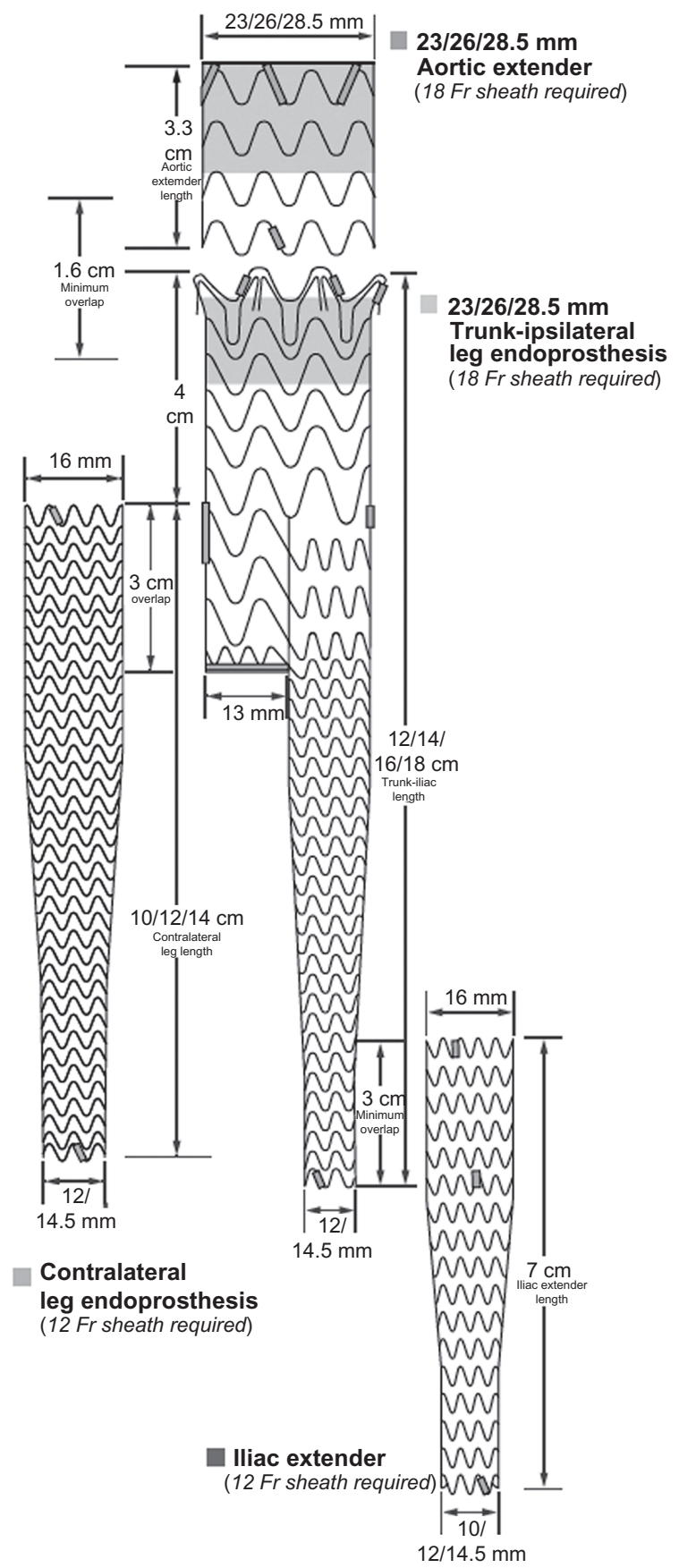

Figure I The Gore EXCLUDER endoprosthesis (WL Gore \& Associates, Flagstaff, AZ). A modular bifurcated design showing assorted limb extension and main body extension stent grafts.

incredibly simple in concept, the accuracy of the "rip-cord" deployment has been contested in the setting of tortuous aortic anatomy. The rapid deployment of a self-expanding device in the setting of angulation and path rotation has resulted in occasional imprecise landing. In these circumstances, the Excluder device tends to land short of the desired target and a proximal extension cuff needs to be placed. While evidence suggests that the original iteration of the Excluder 
deployment was highly accurate, ${ }^{13}$ competing manufacturers have stressed that their systems perform better in that regard by allowing more operator control and precision.

Deemed the C3 delivery system, the new deployment mechanism allows the operator to reposition the Excluder device prior to final release from the delivery catheter up to three times. This is useful in the event that the main body of the Excluder fails to deploy properly, either too high or too low, in relationship to the lowest renal artery. With the C3, the stent-graft main body can be reconstrained following partial deployment, subsequently allowing readjustment of the graft for a more precise proximal landing. This capability may also be useful when gate cannulation proves to be difficult. Simply, if the device position for gate cannulation is unfavorable, the graft can be constrained and rotated into a more favorable position. The Excluder graft itself was unaltered with this delivery system change. Despite its designed application to optimize graft position in hostile aortic neck anatomy, the device IFU did not change with the $\mathrm{C} 3$ modification.

\section{C3 delivery system}

The $\mathrm{C} 3$ delivery system manifold houses the deployment controls as pictured in Figure 2. The outer white casing controls the initial deployment of the proximal trunk of the main body to level of the contralateral gate. When the white outer deployment knob is removed, the constraining mechanism of the device is exposed (transparent handle with a gray turning dial attached at its end). The constraining mechanism controls the closing and reopening of the proximal trunk of the main body. At the time of final device deployment, this constraining mechanism is removed which exposes the final deployment knob. Each component of the $\mathrm{C} 3$ deployment system is relatively straightforward to understand and easy to handle. The use of the $\mathrm{C} 3$ is outlined below.

Cases proceed in the usual fashion with standard retrograde access of the bilateral common femoral arteries. Once measurements are complete and stiff wires placed, the main body is delivered to position below the lowest renal artery. For initial deployment, the outer white casing of the delivery handle is removed with a 90 degree counterclockwise turn followed by steady, continuous pull (Figure 2A). This maneuver deploys the main body of the device to the level of the contralateral gate. If the proximal position is deemed satisfactory, contralateral gate cannulation can be undertaken at this point. If the main body demonstrates malposition, it can be constrained by turning the gray constraining dial clockwise until the dial stops turning (Figure 2B). Turning the gray constraining dial will move the black nut distally as seen through the transparent knob. This confirms the constraining process. Once the graft is fully constrained, the main body can be moved up or down, and can be rotated to reposition gate location as necessary. Once in satisfactory position, the graft is redeployed by turning the gray constraining dial counterclockwise until the dial stops turning (Figure 2C). The black nut will move proximally to its original position in the transparent knob marked by the black line. The graft is then disengaged from the constraining mechanism by releasing the red safety lock and then pulling the entire transparent knob (Figure 2D and E). To complete deployment to the ipsilateral limb, the inner gray knob is then pulled (Figure 2F).

In the event that deployment of the main body fails, the $\mathrm{C} 3$ manifold houses a failure-mode deployment hatch (Figure 3). Located on the main white handle, this hatch can be opened to expose the various wires of the device, including the main body deployment, constraining, and ipsilateral limb deployment wires. Should problems occur, the operator can directly pull the various device wires with a hemostat allowing manual deployment of the endograft at its various stages.

\section{Discussion}

Data regarding the Excluder device with the $\mathrm{C} 3$ deployment system is limited to a single institution experience reported by Verhoeven et al. In their study, Excluder devices were placed using the $\mathrm{C} 3$ deployment system in 25 patients with infrarenal AAA. ${ }^{14}$ The technical success rate was $100 \%$ and operative mortality was zero. The authors used the repositioning capability of the $\mathrm{C} 3$ system in $72 \%$ of the cases to either achieve better proximal landing or to facilitate cannulation of the contralateral limb. Surprisingly, the majority of the repositioning was performed for gate orientation. The authors concluded that the new deployment system made it possible to reposition the Excluder graft to achieve optimal fixation and sealing. A prospective observational registry is set in place (NCT01398332) for ongoing evaluation of the Excluder with the $\mathrm{C} 3$ delivery system. ${ }^{15}$

Although little is known yet regarding the clinical impact of the $\mathrm{C} 3$ delivery system, the long-term cumulative performance with the Excluder graft, which has not been modified, is excellent. Studies have demonstrated very low perioperative morbidity and mortality and excellent protection from aneurysm-related complications ${ }^{8,9}$ From the combined cohort analysis (original ePTFE and low permeability grafts) spanning 5 years within the Excluder Phase II trial, the 30 -day aneurysm-related death rate was $1.8 \%$. None of 
A

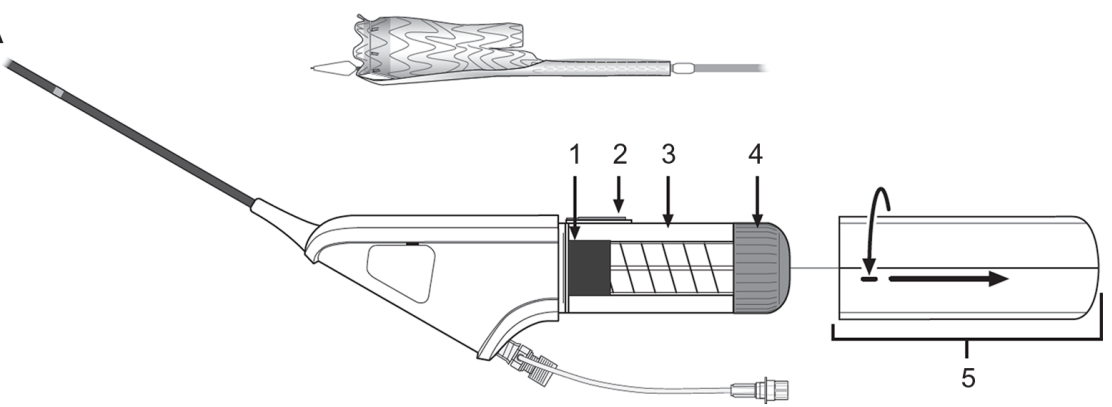

B

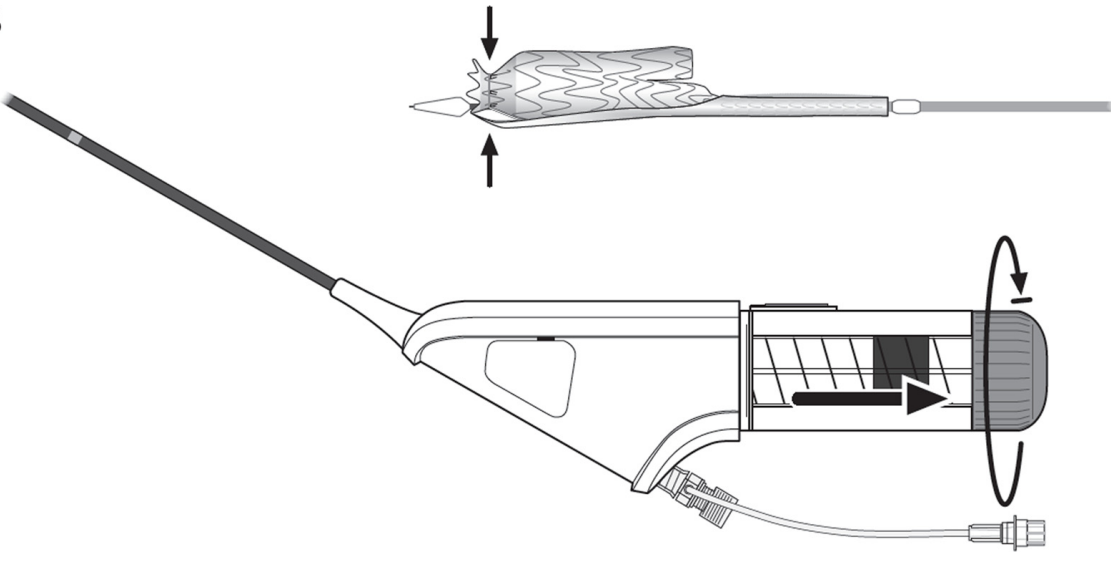

C

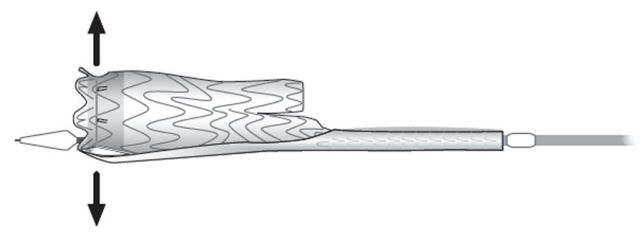

$\checkmark$

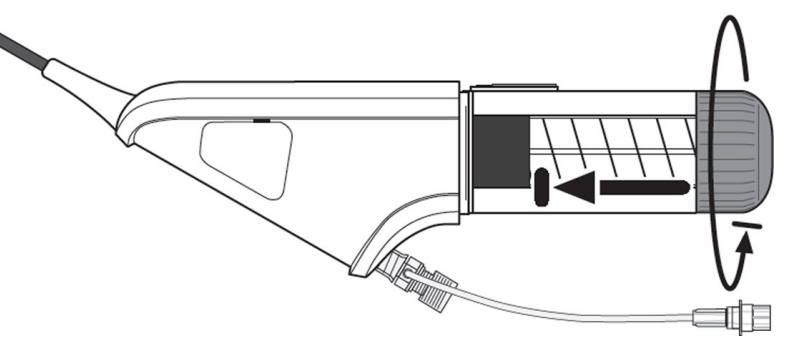

D
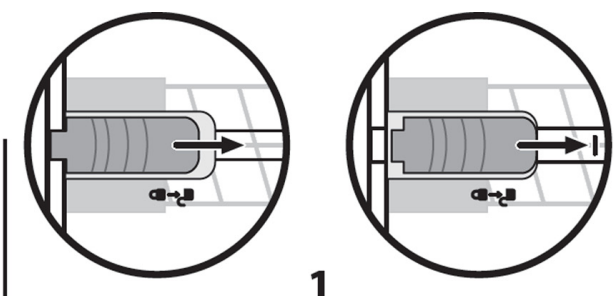

1

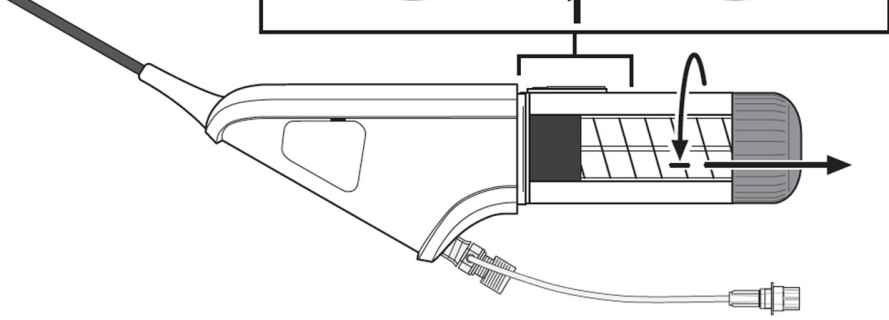

Figure 2 (Continued) 

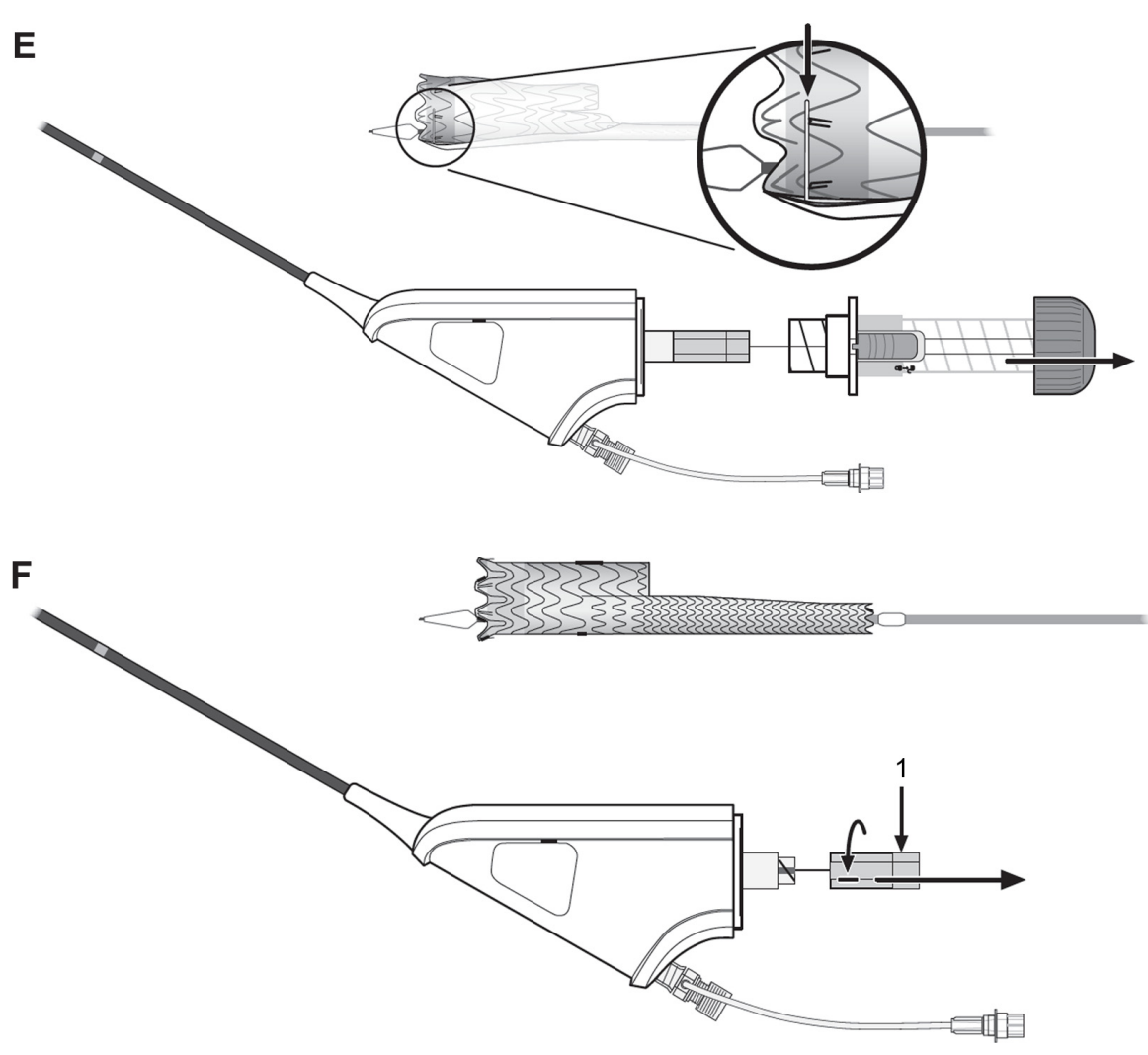

Figure 2 C3 delivery system. (I) black nut; (2) red safety lock; (3) transparent knob; (4) Gray constraining dial; (5) white outer deployment knob. (A) white outer deployment knob is pulled to deploy the proximal trunk; (B) proximal trunk can be constrained using the gray constraining dial; (C) proximal trunk can be reopened using the gray constraining dial; (D) red safety lock is disengaged; (E) transparent knob (constraining mechanism) is pulled to remove the constraining wire; (F) gray deployment knob is pulled to complete deployment of the main body.

these deaths were actually caused by an aneurysm rupture. ${ }^{7}$ The reintervention rate of the Excluder device was 13.8\%, with $72 \%$ of these procedures performed within 12 months of initial placement. ${ }^{7}$ With respect to the proximal seal of the graft in situations of severe neck angulation $>60^{\circ}$, use of the Excluder has resulted in lower reintervention rates when compared with other devices. ${ }^{16}$
With the performance of the Excluder validated, GORE designed the $\mathrm{C} 3$ delivery system to counter the criticisms heaped upon the original "rip-cord" deployment mechanism by changing to a controlled, incremental process. With the original rapid deployment mechanism, the stent-graft deploys from proximal to distal and it opens proximally with a slight expansion of the seam side first (contralateral side).

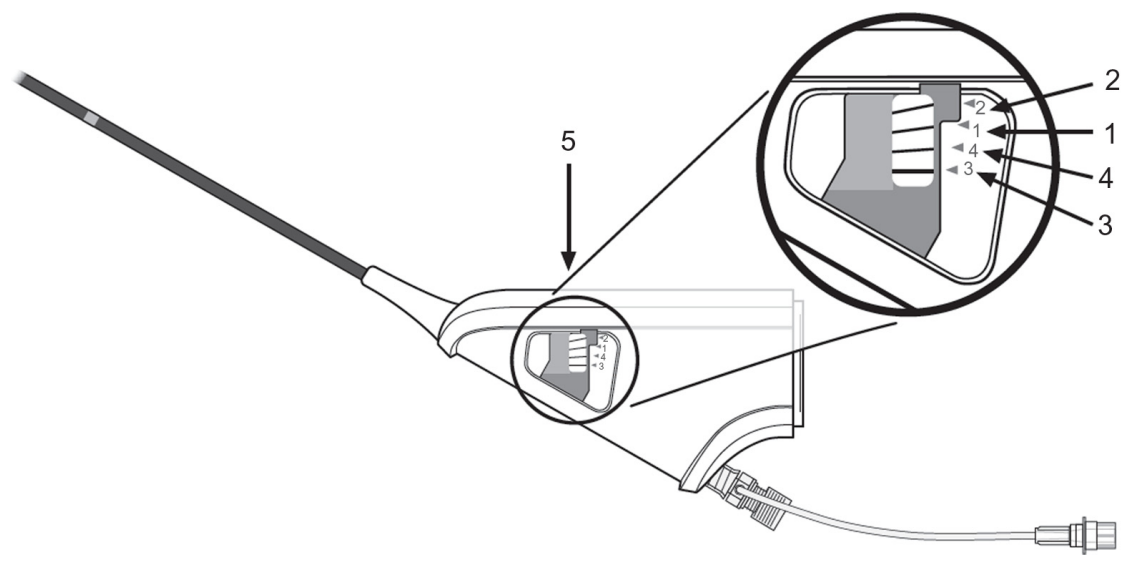

Figure 3 Failure mode safety hatch of the C3 delivery system. (I) First deployment line; (2) lock pin; (3) constraining loop; (4) second deployment line; (5) deployment line access hatch. 
Operators who are familiar with the Excluder have exploited this tendency to optimize the proximal seal in an angulated infrarenal neck. On the down side, given that the graft does not flower symmetrically, it is subject to jumping, either forward and more often distally, during rapid deployment.

Understandably, the unpredictable mechanical tendencies during rapid deployment can be unnerving for the operator who is unfamiliar with the nuances of the Excluder graft. The ability to reposition the device will be heralded by operators who are relatively new to endovascular aortic repair or those who have limited experience using the Excluder device. In effect, repositioning affords operators "peace of mind" in the setting of suboptimal device positioning, especially when faced with learning to handle a new device.

Guiding a wire through the contralateral gate can also be demanding when the aneurysm is large. Cannulation can also be challenging when the contralateral gate fails to open completely, a significant amount of operative time and resources (eg, wires, catheters, radiation exposure) may be spent during this process. The ability to adjust the gate based on wire trajectory can improve efficiency. Results of the ongoing prospective observational study on the $\mathrm{C} 3$ delivery system may elucidate its impact on operative efficiency.

Designed with the intent of expanding the role of endovascular aortic repair to more hostile neck anatomy, the $\mathrm{C} 3$ delivery system could, in effect, increase the number of endovascular aortic repair cases performed outside of device IFU. The Excluder graft's anatomic suitability criteria, as reported in the device IFU, were not altered with the implementation of the C3 delivery system. Mounting evidence has shown that better outcomes occur when endovascular aortic repair is performed within versus outside of device-specific IFU. Leurs et al demonstrated that a neck length $<15 \mathrm{~mm}$ was associated with significantly increased rates of early and late proximal type 1 endoleak. ${ }^{17}$ Likewise, Hobo et al found that endovascular aortic repair in patients with severe aneurysm neck angulation $\left(>60^{\circ}\right)$ had higher rates of early proximal type 1 endoleak, graft migration, and greater late proximal neck dilatation, and reintervention rates. ${ }^{16}$ In a review of their endovascular aortic repair experience, Abruzzese et al stratified patients by IFU status with respect to proximal neck anatomy and found that patients outside IFU experienced higher rates of graft-related adverse events and ultimately a higher rate of perioperative aneurysm-related mortality. ${ }^{6}$

The new C3 deployment system could give clinicians the premise to test the limits of the Excluder IFU, but caution and restraint should be exercised. Historically, graft-related adverse outcomes in cases performed outside IFU may not necessarily be reflective of initial graft positioning, which is the primary endovascular aortic repair variable that the $\mathrm{C} 3$ delivery system is designed to control. Unless future data prove otherwise, one should not assume that the use of the Excluder with the $\mathrm{C} 3$ delivery system will improve overall outcomes in cases outside of device IFU.

\section{Conclusion}

As experience with endovascular aortic repair continues to increase, demand from clinicians has spurred innovations in stent-graft device design that enhance performance in challenging aortic anatomy. Gore has implemented the $\mathrm{C} 3$ deployment system to improve control and precision during device implantation and build upon their excellent results with the Excluder endograft. Limited evidence does demonstrate improved ease of use, safety, and efficacy with the new device design.

\section{Disclosure}

MDM receives research support and honoraria for serving as a training course director from WL Gore and Associates Inc.

\section{References}

1. Lederle FA, Johnson GR, Wilson SE, et al. The aneurysm detection and management study screening program: validation cohort and final results. Aneurysm Detection and Management Veterans Affairs Cooperative Study Investigators. Arch Intern Med. 2000;160:1425-1430.

2. Parodi JC, Palmaz JC, Barone HD. Transfemoral intraluminal graft implantation for abdominal aortic aneurysms. Ann Vasc Surg. 1991;5: 491-499.

3. Lederle FA, Freischlag JA, Kyriakides TC, et al. Outcomes following endovascular vs open repair of abdominal aortic aneurysm: a randomized trial. JAMA. 2009;302:1535-1542.

4. EVAR Trial Participants. Endovascular aneurysm repair versus open repair in patients with abdominal aortic aneurysm (EVAR trial 1): randomised controlled trial. Lancet. 2005;365:2179-2186.

5. van Marrewijk CJ, Leurs LJ, Vallabhaneni SR, Harris PL, Buth J, Laheij RJ. Risk-adjusted outcome analysis of endovascular abdominal aortic aneurysm repair in a large population: how do stent-grafts compare? J Endovasc Ther. 2005;12:417-429.

6. Abbruzzese TA, Kwolek CJ, Brewster DC, et al. Outcomes following endovascular abdominal aortic aneurysm repair (EVAR): an anatomic and device-specific analysis. J Vasc Surg. 2008;48:19-28.

7. WL Gore and Associates INC, GORE ${ }^{\circledR}$ Excluder $^{\circledR}$ AAA Endoprosthesis annual clinical update. http://www.goremedical.com/resources, February 2011.

8. Curci JA, Fillinger MF, Naslund TC, Rubin BG. Clinical trial results of a modified gore excluder endograft: comparison with open repair and original device design. Ann Vasc Surg. 2007;21:328-338.

9. Bos WT, Tielliu IF, Van Den Dungen JJ, et al. Results of endovascular abdominal aortic aneurysm repair with selective use of the Gore Excluder. J Cardiovasc Surg (Torino). 2009;50:159-164.

10. Fillinger M. Three-dimensional analysis of enlarging aneurysms after endovascular abdominal aortic aneurysm repair in the Gore Excluder pivotal clinical trial. J Vasc Surg. 2006;43:888-895.

11. Haider SE, Najjar SF, Cho JS, et al. Sac behavior after aneurysm treatment with the Gore Excluder low-permeability aortic endoprosthesis: 12-month comparison to the original Excluder device. J Vasc Surg. 2006;44:694-700. 
12. Tanski W 3rd, Fillinger M. Outcomes of original and low-permeability Gore Excluder endoprosthesis for endovascular abdominal aortic aneurysm repair. J Vasc Surg. 2007;45:243-249.

13. Whittaker DR, Dwyer J, Fillinger MF. Prediction of altered endograft path during endovascular abdominal aortic aneurysm repair with the Gore Excluder. J Vasc Surg. 2005;41:575-583.

14. Verhoeven EL, Oikonomou K, Mohner B, Renner H, Ritter W. First experience with the new repositionable $\mathrm{C} 3$ excluder stent-graft. J Cardiovasc Surg (Torino). 2011;52:637-642.

15. WL Gore and Associates. Evaluation of the GORE ${ }^{\circledR} \mathrm{C} 3$ delivery system module. In: ClinicalTrials.gov [Internet]. Bethesda, MD: National Library of Medicine (US). July 18, 2011 [last updated on July 19, 2011]. Available from: http://clinicaltrials.gov/ct2/show/NCT01398332. NLM identifier: NCT01398332.
16. Hobo R, Kievit J, Leurs LJ, Buth J. Influence of severe infrarenal aortic neck angulation on complications at the proximal neck following endovascular AAA repair: a EUROSTAR study. J Endovasc Ther. 2007;14:1-11.

17. Leurs LJ, Kievit J, Dagnelie PC, Nelemans PJ, Buth J. Influence of infrarenal neck length on outcome of endovascular abdominal aortic aneurysm repair. J Endovasc Ther. 2006;13:640-648.
Open Access Surgery

\section{Publish your work in this journals}

Open Access Surgery is an international, peer-reviewed, open access journal that focuses on all aspects of surgical procedures and interventions. Patient care around the peri-operative period and patient outcomes post surgery are key topics. All grades of surgery from minor cosmetic interventions to major surgical procedures are covered. Novel techniques

Submit your manuscript here: http://www.dovepress.com/open-access-surgery-journal

\section{Dovepress}

and the utilization of new instruments and materials, including implants and prostheses that optimize outcomes constitute major areas of interest. The manuscript management system is completely online and includes a very quick and fair peer-review system. Visit http://www.dovepress.com/ testimonials.php to read real quotes from published authors. 